\title{
Problemas em intervenções de conservação e restauro. Como evitá-1os?
}

\author{
Filipa Raposo Cordeiro
}

Resumo: Uma vez criado, o Património Cultural sofre alterações mais ou menos acentuadas consoante os factores de degradação a que é sujeito. A pintura quinhentista "Visitação", do pintor Thomás Luis, não foi excepção. Comportou ao longo de quatro séculos transformações a nível físico, químico, histórico e estético, devido a factores extrínsecos: ambiental, biológico e humano, tendo este último maior reflexo na alteração da integridade da obra. Este artigo está dividido em três partes. Na primeira, destacamos a patologia lixiviação observada no case study referido. $\mathrm{Na}$ segunda, com o apoio de análises, procuramos identificar o contexto histórico da ocorrência. Na última parte, com o objectivo de evitar problemas de conservação e restauro, propomos directrizes de consciencialização de proprietários de bens culturais, futuros conservadoresrestauradores, curadores ${ }^{1}$, historiadores de arte, arquitectos e público em geral, que envolvem acções de: formação actualizada sobre os conteúdos da Conservação e Restauro e o valor da interdisciplinaridade; inspecção e assistência.

Palavras-chave:Pintura, conservação, restauro, análises, factor humano, lixiviação, formação, interdisciplinaridade.

Resumen: Desde su génesis el Patrimonio Cultural sufre alteraciones más o menos acentuadas en función de los factores de degradación a que está sometido. La pintura quinientista "Visitación" del pintor Thomás Luis no fue excepción. A lo largo de cuatro siglos sumó modificaciones de orden físico, químico, histórico y estético, debido a factores extrínsecos: ambiental, biológico y humano, donde este último tuvo el mayor peso. Este artículo se divide en tres partes. En la primera, destacamos la patología lixiviación de la que ha padecido la obra. En la segunda, con el apoyo de análisis, procuramos identificar el contexto histórico de tal ocurrencia. En la última parte, con el objetivo de evitar problemas de conservación y restauración, proponemos directrices de concienciación de propietarios de bienes culturales, futuros conservadores-restauradores, curadores, historiadores del arte, arquitectos y público en general, que están implicados en acciones de: formación actualizada sobre los contenidos de Conservación y Restauro y el valor de la interdisciplinariedad; inspección y asistencia.

Palabras clave: Pintura, conservación, restauración, análisis, factor humano, lixiviación, formación, interdisciplinariedad.

\begin{abstract}
Since its genesis Cultural Heritage suffers more or less evident alterations depending on degradation factors. The $16^{\text {th }}$ century panel "Visitation" by Thomás Luis was no exception. It tolerated modifications in its physical, chemical, historical and aesthetic integrity over four centuries, under the environmental, biological and human factors, but mainly the latter. This article is divided in three parts. In the first part, we highlight the pathology leaching present in the mentioned case study. In the second, based on scientific analysis we intend to identify, the historic context in which such damage occurred. In the last part, with the goal of avoiding conservation and restoration problems, we propose awareness directives for artwork owners, students of conservation-restoration, curators, art historians, architects and the general public to avoid conservation problems, including several actions: updating education contents regarding Conservation and Restoration and the value of an interdisciplinary approach; inspection and assistance.
\end{abstract}

Keywords: Painting, conservation, restoration, analyses, human factor, leaching, education and training, interdisciplinary. 


\section{1 - Problemas de conservação e restauro}

Em Janeiro de 2010, no Seminário de doutoramento "Coordenação de Projecto de Investigação I" leccionado no Instituto de História da Arte (IHA) da Faculdade de Letras de Lisboa (FLUL), Vítor Serrão apresentou o caso do retábulo maneirista de Giraldo Fernandes de Prado (c. 1530-1592) pertencente à Santa Casa da Misericórdia de Almada (Serrão 2008: 143), em processo de conservação e restauro, bem como um documento datado de 1757 que menciona os materiais (incluindo pigmentos, cargas e aglutinante), utilizados pelos "pintores" lisboetas José Nunes e João Gomes Baptista, para o 'restauro' desse mesmo retábulo que o terramoto danificara (Serrão 2006: $62)$.

A preocupação com a conservação e restauro da pintura de Giraldo, 'restaurada' em meados do século XVIII, suscitou um debate entre os alunos, a partir de duas questões: Como se sabe quais são as cores originais? Qual o critério na conservação e restauro de uma pintura com um 'restauro' antigo que cobre parte ou a sua totalidade?

Como resposta àquelas perguntas, os discentes forneceram pistas: cada intervenção deverá ser precedida e acompanhada por um estudo interdisciplinar, alicerçado nas descobertas fornecidas pelo arquivo e por métodos de exame e análise; é fundamental existir a "consciencialização" do valor da cooperação entre os vários especialistas da equipa pluridisciplinar (conservadoresrestauradores, curadores, historiadores de arte, químicos, físicos e arquitectos).

No seguimento daquele debate e através do case study do painel "Visitação" de Thomás Luis, escrevemos o presente artigo, partindo de estudos que incluem reflexões no sentido de evitar problemas em intervenções de conservação e restauro (Serrão 2003, cit. Cruz 2005: 43; Cruz 2005: 29-53; Cordeiro 2009 a: 70-75, 2009 b: 22-35).

A "Visitação", única pintura 'de cavalete' de Thomás Luis, descoberta até hoje, pertence à igreja da Santa Casa da Misericórdia (SCM) da antiga Aldeia Galega do Ribatejo (actual Montijo). Em 20032004, a obra foi alvo de um estudo e de uma criteriosa intervenção de conservação e restauro interdisciplinar (Cordeiro 2005: 51-87, 2010 a: 73-87). Das numerosas alterações diagnosticadas, salientamos na primeira parte deste artigo uma patologia grave, a evitar, observada na camada pictórica3: a lixiviação.

\section{1 - Lixiviação}

A terminologia lixiviação, não mencionada em certos glossários multilingues (Mendonça et. al. 1993; CCI 1994), mas utilizada em estudos internacionais (Bergeon 1990: 119-120; Calvo 1997: 135) e retomada por nós (Cordeiro 2004: 202; 2005: 62; 2010 a: 86), refere-se a uma patologia irreversível causada por uma intervenção de limpeza inadequada.

Um solvente ou mistura "com afinidade química tanto com os materiais a remover como com aqueles a preservar ... causa a distensão das camadas cromáticas originais, na sua espessura, e o consequente enfraquecimento do aglutinante quando exposto às moléculas do solvente. Quando o solvente evapora dá-se a contraçãa das camadas cromáticas e a consequente perda de aglutinante e de pigmento" (Cordeiro 2010 a: 86). O grau de lixiviação depende do tipo de solvente utilizado, do tempo de contacto do solvente com o substrato, e da espessura e da natureza deste último (Cordeiro 2010 b).

A camada pictórica original da "Visitação", constituída por preparação, camada de impressão4, camadas cromáticas e verniz - que poderia ser o não original (entretanto removida) -, contendo uma carga, pigmentos orgânicos e inorgânicos e aglutinantes proteicos e oleoso, apresentava uma camada posterior de cor branca que cobria parcialmente o conjunto pictórico (A). Numa intervenção de limpeza, um solvente aplicado sobre esta camada de tinta branca a remover, 
amoleceu não só esse estrato como os subjacentes (B), acabando por provocar a perda de material original, i.e., a diminuição da espessura da camada pictórica (C) [figura 1].
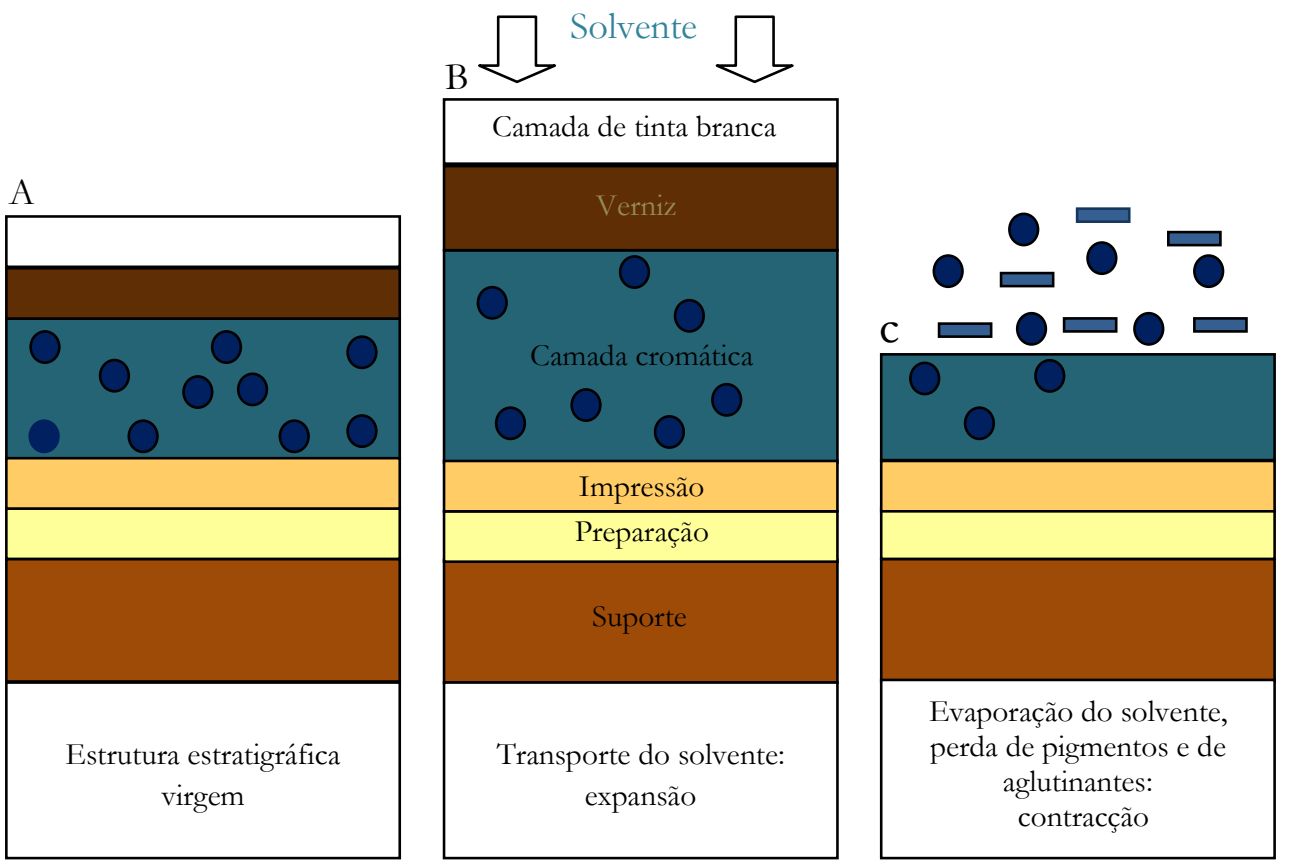

Figura 1. Lixiviação da camada pictórica da "Visitação" de Thomás Luis.

Embora a técnica de Thomás Luis demonstrasse que foram respeitadas as regras base, a pintura apresentar em geral uma excelente adesão entre os estratos e uma notável coesão entre as partículas e os aglutinantes, cerca de $90 \%$ da área total da superfície pictórica apresentava-se em calamitoso estado de conservação, quase sem a "epiderme"(termo utilizado por Luciano Freire, referente a um dano causado em certas pinturas devido a "limpeza brutal" - Cruz 2007: 71-72). Observavam-se lacunas de diferentes dimensões e níveis de profundidade [figura 2].

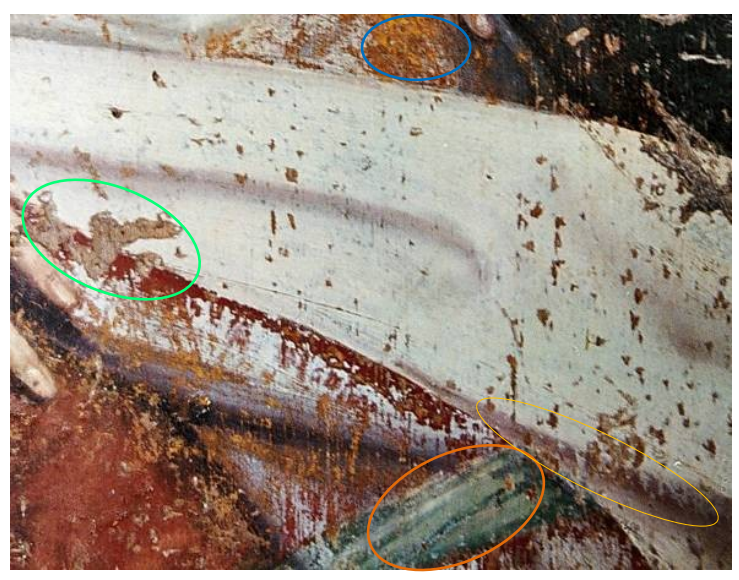

Figura 2. Thomás Luis, Visitação, 1591-92. Lixiviação da camada pictórica, perda de:

- Velaturas;

- Velaturas e camadas cromáticas até se observar pintura de construção ${ }^{2}$ subjacente;

- Camadas cromáticas até se observar a impressão corada;

- Impressão e preparação até se observar o suporte. 
Apenas se apresentavam intactas as zonas protegidas com verniz, correspondentes a cerca de $10 \%$ da frente da pintura [figura 3].

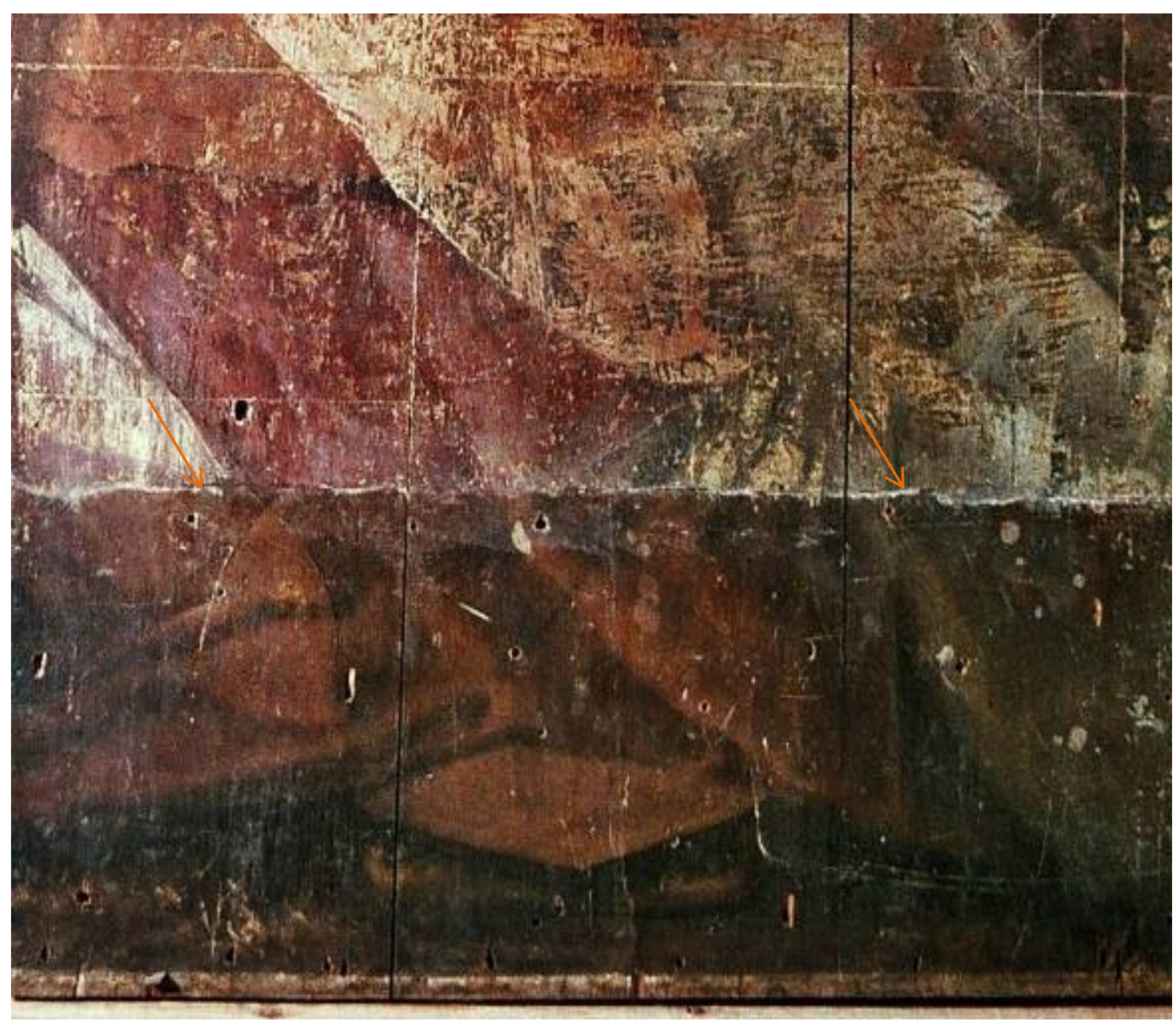

Figura 3. Thomás Luis, "Visitação". Vestes de Santa Isabel após uma intervenção de limpeza duvidosa. De notar duas zonas com diferentes estados de conservação, intercaladas por uma fina linha residual da tinta branca: a zona superior lixiviada, com perda de velaturas e de camadas cromáticas violeta, carmim, cor-de-laranja e cinzenta; e a zona inferior da área em apreço, ainda com uma camada de verniz, com oxidação fotoquímica acentuada, por remover (diagnóstico de 2003).

\section{2 - Problemas de conservação e restauro na "Visitação" de Thomás Luis: contexto histórico}

Durante o seu tempo de vida, os bens culturais são em geral sujeitos a intervenções de conservação e restauro, nocivas na ausência de critérios científicos.

Para compreender a razão da lixiviação na "Visitação" de Thomás Luis é fundamental conhecer a história trans-memorial da obra.

A "Visitação" foi concebida em 1591-1592, teve o seu período de apogeu, ao qual se sucedeu um de decadência e por fim uma inesperada ressurreição. Provavelmente terá permanecido em bom estado de conservação durante um século e meio após a sua feitura, pois um documento de 1710 refere obras na igreja realizadas pelo pedreiro Amaro dos Santos, mas nada refere sobre a 
"Visitação". Dois anos após o grande terramoto em Lisboa (1755), realizaram-se grandes obras na capela-mor da igreja, infelizmente não descriminadas. No decorrer dessas obras, é plausível que a pintura tenha sido removida do seu local original de exposição e tratada com incúria, pois em 1768 já se encontrava em "estado de velhice e incapacidade" (Serrão 2005: 22). Em 1789-90, a SCM da Aldeia Galega contratou o carpinteiro Eusébio dos Santos e o pintor-dourador Matias Gomes Neto para realizar uma obra no altar-mor. A ajuizar pelas longas incisões verticais, horizontais e semicirculares (marcas de compasso) que a "Visitação" apresentava na frente, cuidamos que nessa época a pintura, anteriormente dada como 'inútil', terá sido utilizada como mera superfície de trabalho. Em 1799, quando o pintor Manuel António Araújo foi contratado para realizar uma nova "Visitação" para a boca da tribuna, a obra de Thomás terá tido uma segunda função: fazer de parede de forro da tribuna do ulterior retábulo setecentista. Observando as lacunas no suporte do painel percebemos que, com aquele propósito, a pintura foi mutilada, tendo sido cortada e desbastada (na frente - zona lateral direita -, e no reverso), e as suas travessas arrancadas (deixando alguns dos cravos que as prendiam no painel). O painel de Thomás Luis foi então colocado na tribuna e recebeu a aplicação de uma tinta branca nas superfícies expostas, acessíveis. O suporte da obra sofreu outrora um ataque biológico pontual de insectos xilófagos, diagnosticado em 2003, não se podendo precisar a sua datação. A pintura ficou esquecida, durante dois séculos até ao seu providencial achamento em 1998. Seguiram-se duas intervenções de conservação e restauro no espaço de meia década.

Questionámo-nos se a lixiviação, causada por limpeza(s) acrítica(s), teria sido provocada nos séculos XVII-XVIII (plausivelmente c. 1799, aquando da alteração da função da "Visitação": de pintura para parede), ou posteriormente.

Nos "Segredos Necessários para os Officios, Artes, e Manufacturas", da Oficina lisboeta de Simão Thaddeo Ferreira, do ano de 1794, encontra-se uma receita que recomenda: "se o painel fồ antigo he necessário alimpalo com uma brocha bum pouco áspera, molhada em lexivia tépida, composta de uma camada de água do rio e de buma quarta de sabão negro (...). Para renovar buma pintura velha lava a pintura três ou quatro vezes com agua de cal. Quando bum painel está novo, dá-se vivacidade ás côres do modo seguinte. Dissolve bum bocado de assucar candi (...) na (...) agoa ardente (...) [junta] uma clara de ovo (...) e passa (...) por cima do painel buma esponja fina (...) molhada neste licor." (Serrão 2006: 57-58). Receituários como este eram conhecidos naquela época por 'pintores-restauradores'.

Poderíamos pensar que alguns dos agentes de limpeza acima referidos fossem os responsáveis por parte da lixiviação. No entanto temos dados que validam outra explicação para esses danos. Detectámos que a lixiviação não estava presente em toda a superfície da obra. Por que não existia lixiviação nas zonas que ainda apresentavam verniz? Qual a razão da 'linha branca' presente em certas zonas da pintura [figura 3]?

Após árdua investigação, conseguimos apurar que o primeiro tratamento da "Visitação" foi realizado em duas fases. Na primeira fase, realizou-se a limpeza da camada cromática e, na segunda, o tratamento do suporte e o retoque monocromático cor-de-rosa claro (com repinte pontual Cordeiro 2010 b: 85 e 88) [figura 5]. Documentação fotográfica respeitante à primeira fase demonstrou que a tinta branca que cobria parte da obra foi removida com a pintura ainda no forro da tribuna setecentista [figura 4]. Este facto explica por que razão se observavam linhas de acumulação da dita tinta branca, entre as zonas limpas, infelizmente em calamitoso estado de conservação, e as zonas por limpar, que estavam em razoável estado de conservação, possivelmente devido à falta de acesso [figura 5]. 


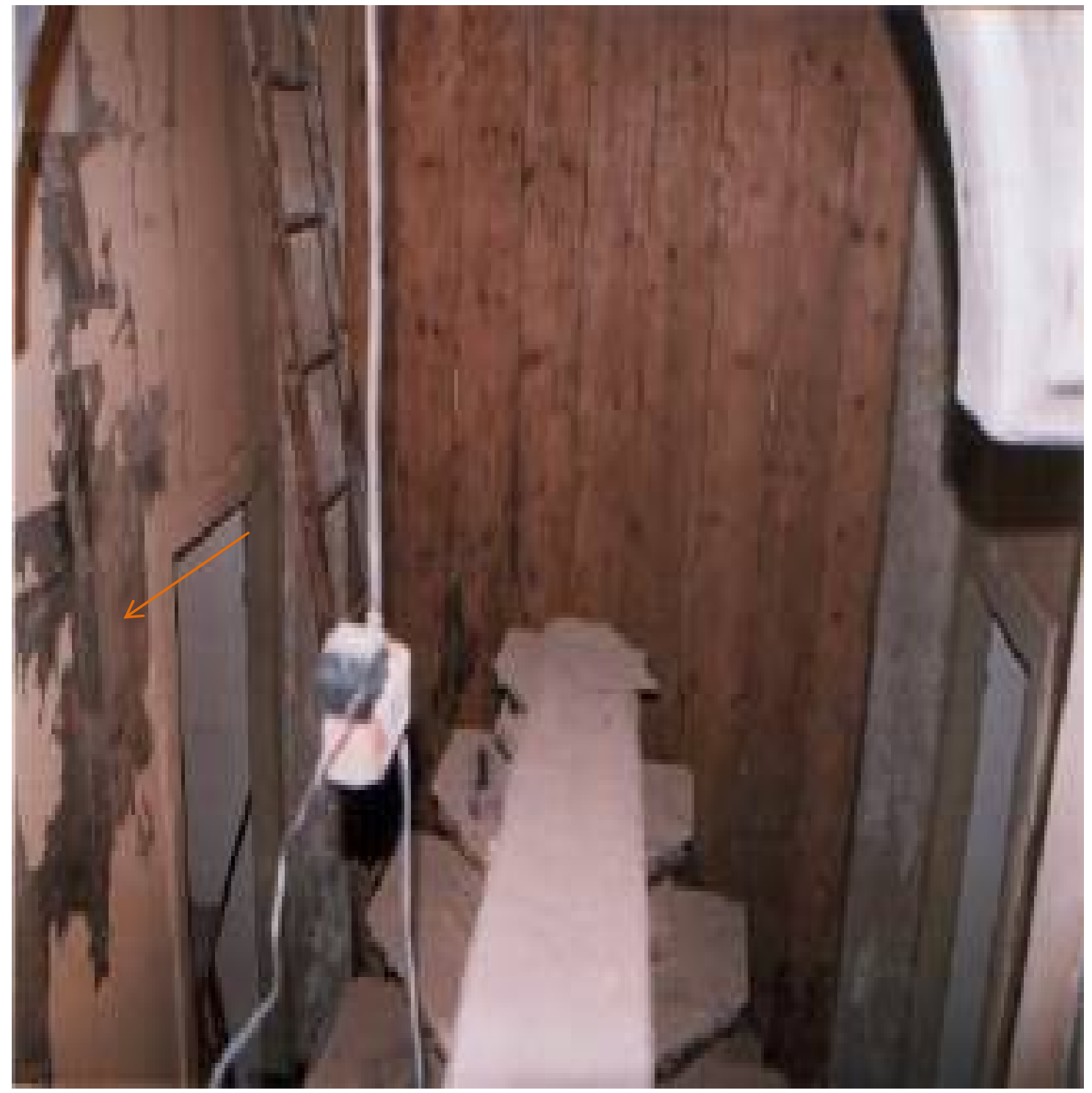

Figura 4. Descoberta da pintura "Visitação", de Thomás Luis, no forro lenhoso da tribuna do retábulo setecentista. Primeira fase da intervenção de 1998- remoção da camada branca existente sobre a pintura escondida.

Encontrámos portanto a explicação para a presença das 'linhas verticais e horizontais', fronteiras entre as zonas limpas e as por limpar. Estas 'linhas' haviam sido provocadas durante a limpeza da pintura na tribuna, antes de remover as tábuas que constituíam o painel, para proceder à segunda fase do tratamento: a conservação curativa do suporte.

Mas permaneceu uma questão em aberto: porque terão sido removidas as camadas cromáticas originais em zonas demarcadas, deixando a descoberto arrependimentos e pintura de construção de Thomás Luis [figura 5] 


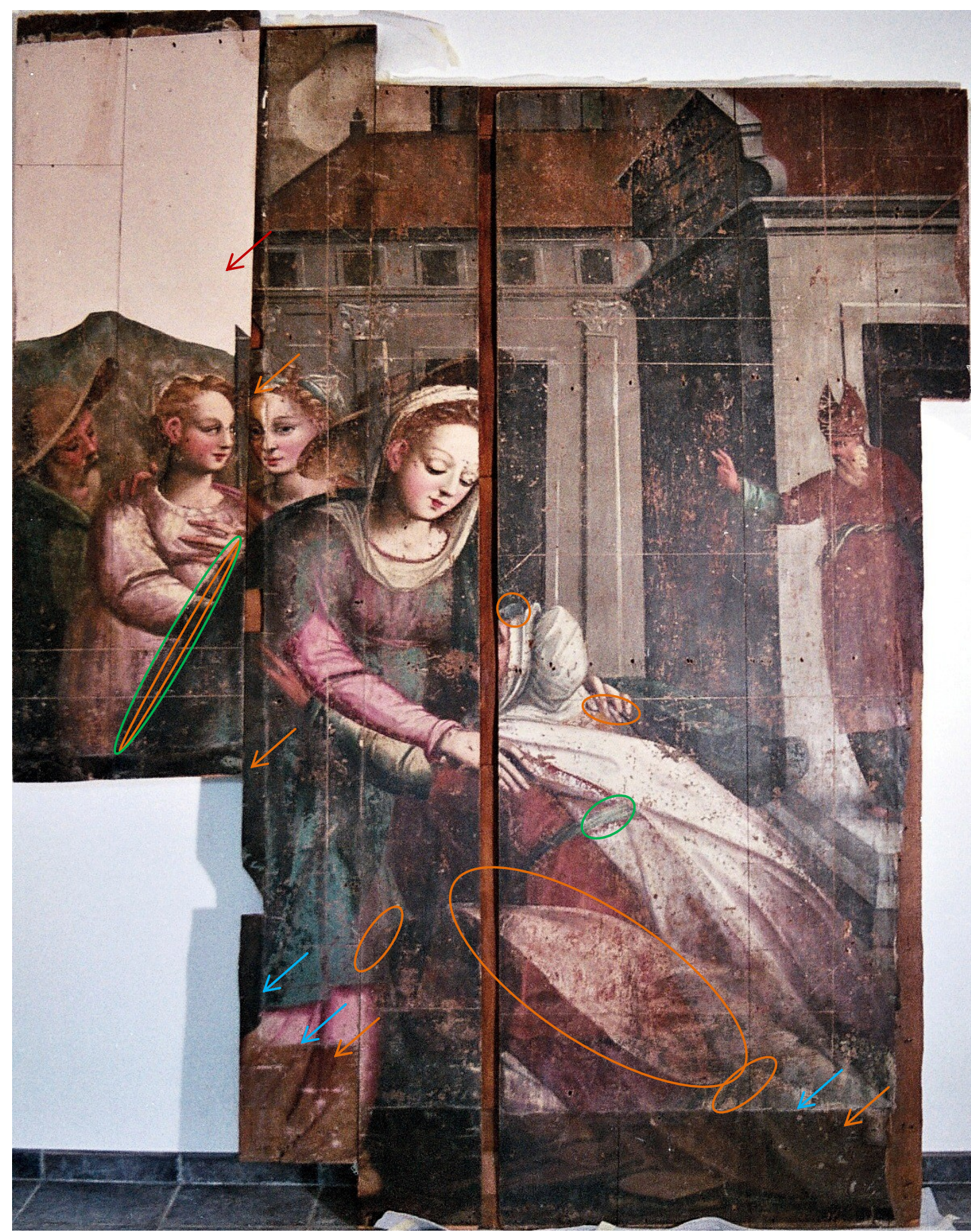

Figura 5. Thomás Luis, "Visitação”, Alt. 291,5 x Larg. 212 (cm), igreja da Misericórdia da antiga Aldeia Galega, 1591 1592. Painel após o tratamento realizado em 1998.

Observam-se:

$\rightarrow \quad$ - zonas com verniz por remover (únicas áreas com a camada cromática subjacente em bom estado de conservação);

$\rightarrow \quad$ - retoque monocromático cor-de-rosa (com repinte pontual);

$\rightarrow \quad$ - resíduos de tinta branca ('linhas verticais e horizontais');

$\bigcirc$ - arrependimentos;

- pintura de construção. 
Parte da resposta está na legendagem da documentação fotográfica do relatório da intervenção de 1998, que revela que a remoção das camadas cromáticas em zonas demarcadas não foi acidental, mas sim consciente: "Fig. 23 - Interior do altar-mor, após remoção de três camadas pictóricas" (SCMM, 2004: 1).

A que estratos corresponderiam as "três camadas pictóricas" referidas?

No sentido de entender melhor a pintura de Thomás Luis, a técnica original e a intervenção de 1998, efectuámos exames e análises de ponto, em oito locais criteriosamente seleccionados. Uma das amostras foi recolhida na zona do panejamento que atravessa a veste de Santa Isabel, que ainda expunha as camadas cromáticas superficiais [figuras 6 e 7]. A análise do corte estratigráfico dessa amostra, por meio de microscopia óptica com e sem luz polarizada (PLM e OM), veio demonstrar que a camada pictórica nesta zona desgastada era composta originalmente por duas finas camadas cromáticas superficiais, uma cor-de-laranja acastanhada e uma cor-de-laranja rosada, sobre uma muito espessa $(121 \mu \mathrm{m})$ à base de branco de chumbo e de uma fina cor-de-laranja. Por espectroscopia de infra-vermelho com transformada de Fourrier (FTIR), detectámos que todos os estratos pictóricos mencionados apresentavam os mesmos aglutinantes, óleo e proteínas de ovo observados nas respectivas bandas de absorção [figuras 8 e 9]. Os resultados das análises por FTIR complementados com testes micro químicos (MT) permitiram constatar que o pigmento branco de chumbo está presente em todas as camadas e que o pigmento ocre amarelo existe nas camadas $\mathrm{n}^{\circ} 1$, $\mathrm{n}^{\circ} 3$ e n $\mathrm{n}^{\circ}$ [tabela 1$]$.

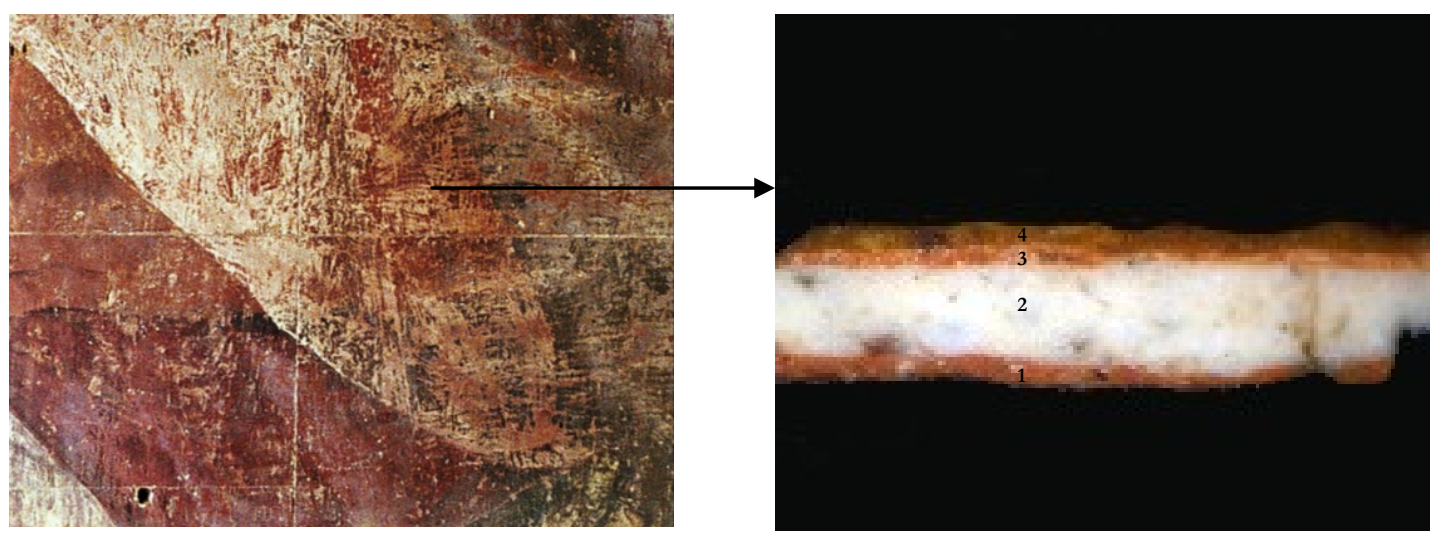

Figura 6. Lixiviação na veste de Santa Isabel que tornou visível um arrependimento de grande dimensão: o panejamento bege que atravessa a túnica cor-de-laranja e a sub túnica de tom carmim avioletado.
Figura 7. Corte transversal: visualizam-se duas finas camadas cromáticas, cor-de-laranja (4) e cor-de-rosa (3), sobre um estrato espesso branco (2) e uma camada subjacente cor-de-laranja (1).

Os resultados das análises laboratoriais vieram confirmar que a técnica presente nos escassos vestígios das camadas cromáticas 'desgastadas' na veste da Santa Isabel é contemporânea das camadas subjacentes, i.e., trata-se da pintura do mesmo artista: Thomás Luis.

Então porque terão sido sacrificadas camadas cromáticas originais na zona estudada e noutras zonas também correspondentes a arrependimentos ou a pintura de construção?

No processo da descoberta da "Visitação" terão os arrependimentos antes tenuemente visíveis feito supor aos técnicos, responsáveis pela limpeza, a existência de outra pintura subjacente mais antiga, talvez um 'primitivo', conduzindo ao levantamento imprudente de "três camadas pictóricas"(SCMM, 2004: 1) em diversas zonas da pintura [figura 10]? 


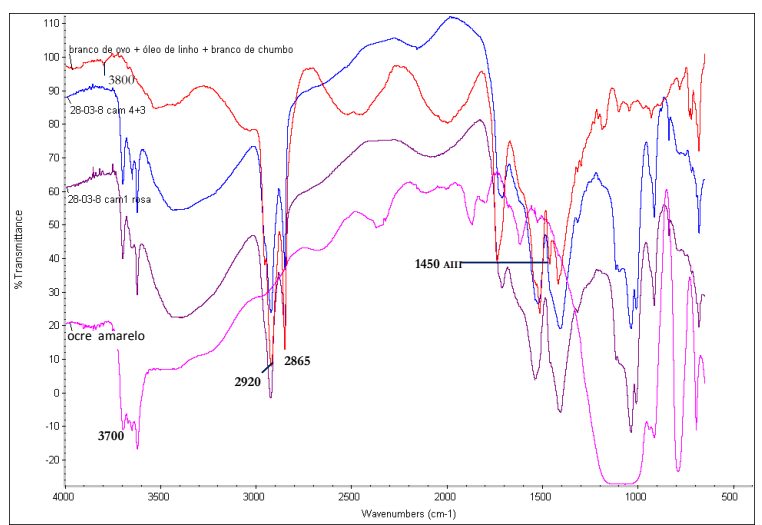

Figura 8. Espectro I (camadas 1, 3 e 4) - branco de chumbo; ocre amarelo; óleo e clara de ovo.

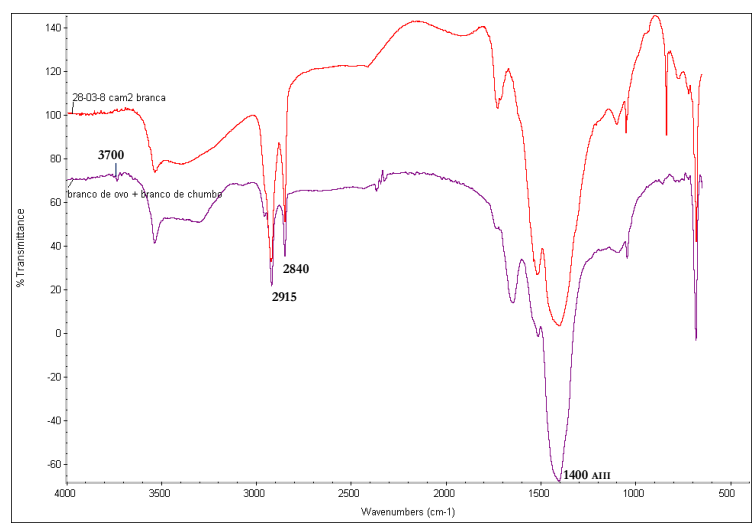

Figura 9. Espectro II (camada 2 - arrependimento) branco de chumbo, óleo e clara de ovo.

Tabela 1

\begin{tabular}{ll}
\hline$\frac{\text { Camadas }}{\mathbf{n}^{\circ} / \text { cor/dimensão }}$ & $\begin{array}{l}\text { Composição } \\
\text { OM/ PLM/ MT / FTIR }\end{array}$ \\
\hline 1 - Cor-de-laranja, $20 \mu \mathrm{m}$. & $\begin{array}{l}1-\text { Branco de chumbo; ocres amarelo, vermelho e } \\
\text { castanho; carvão vegetal; óleo e clara de ovo. }\end{array}$ \\
2 - Branca, $121 \mu \mathrm{m}$ (arrependimento) & 2 - Branco de chumbo; óleo; clara de ovo. \\
3 - Cor-de-laranja rosada, $25 \mu \mathrm{m}$ & $\begin{array}{l}3-\text { Branco de chumbo; ocres amarelo e vermelho; óleo e } \\
\text { clara de ovo. }\end{array}$ \\
4 - Cor-de-laranja, $23 \mu \mathrm{m}$ & $\begin{array}{l}4-\text { Branco de chumbo; ocres amarelo e castanho; óleo e } \\
\text { clara de ovo. }\end{array}$ \\
\hline
\end{tabular}

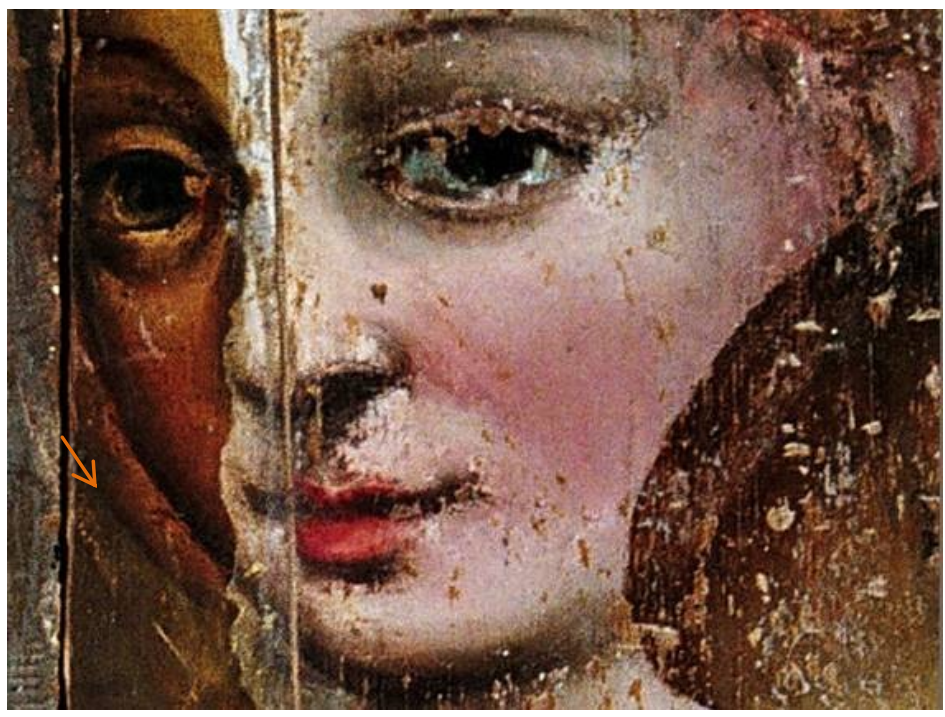

Figura 10. Thomás Luis, "Visitação". Arrependimento no rosto da segunda personagem feminina ainda coberto por uma fina camada de verniz e por velaturas superficiais. 
Plausivelmente os técnicos julgaram estar diante de uma pintura com uma 'remodelação', i.e., com pintura ulterior que teria alterado o tema, a paleta, a proporção anatómica, as poses e/ou os panejamentos das personagens. Temos conhecimento de intervenções em obras, realizadas por questões históricas, estilísticas ou ideológicas (pudor ou reforma doutrinária) ou ainda estéticas (moda e gosto). O termo 'remodelação' é aqui apresentado para diferenciar este tipo de acções dos 'restauros' que, segundo estudos de Tollon e Perusini, surgem em geral no século XIX, época em que Boito dá os primeiros passos no sentido do 'restauro científico'.

Porque terá a limpeza sido parcial, deixando verniz por remover sobre a superfície da obra (grandes extensões e resíduos dispersos)? Terá o tratamento sido interrompido, ou terão os técnicos considerado que estava concluído?

É provável que, em 1998, o critério da limpeza já tivesse sido tomado antes de ser conhecida a técnica da "Visitação" e serem ponderadas as contra indicações do tratamento. A presença de uma etapa de restauro, o retoque, normalmente consecutivo às operações de conservação curativa, foi efectuado antes da conclusão da remoção do verniz degradado, mostrando-nos que, provavelmente, o tratamento foi considerado como concluído.

Um estudo referente à primeira intervenção de conservação e restauro na "Visitação", de Thomás Luis, depois da sua descoberta, narra que o "trabalho (...) contribuiu numa primeira fase para ampliar as feridas na tábua Visitação, através de uma intervenção infelizmente não avisada (e não acompanhada)" (Serrão 2002: 229). Recentemente conseguimos reunir mais um dado que corrobora a avaliação no estudo acima referido. O retoque monocromático (com repinte pontual) realizado em 1998 no canto superior esquerdo da pintura de Thomás velava uma lacuna de grande dimensão que abrangia a totalidade da camada pictórica e parte do suporte. Esta alteração teria sido causada, a avaliar pela forma semi-circular das marcas no suporte, por uma "rebarbadora eléctrica" (Cordeiro 2005: 63). Em Maio deste ano conseguimos confirmar a nossa dedução, aquele dano foi realmente provocado por "uma rebarbadora eléctrica com lixa n'4", durante a descoberta da "Visitação" (Lopes 2010), na tentativa de eliminar certo(s) estrato(s) pictóricos.

Situações deste tipo, a descoberta de quadros totalmente escondidos por pinturas ulteriores, foram detectadas com alguma frequência nas décadas de 1960 e 1970 no Museu Nacional de Arte Antiga, ou no antigo Instituto José de Figueiredo (actual IMC IP). Em todos os casos foi tomada a decisão de levantamento integral das pinturas superficiais (Cruz 2005: 29-53). Foram desta forma descobertas algumas pinturas portuguesas do século XV. Parece que a maior antiguidade das pinturas subjacentes foi um factor decisivo nestes casos, apostando na possibilidade de adquirir novos conhecimentos sobre épocas mais remotas da arte da Pintura.

\section{3 - Como evitar problemas em intervenções de conservação e restauro?}

Parece-nos que os problemas das intervenções de conservação e restauro surgem pelo desconhecimento por parte das entidades proprietárias, sejam particulares ou responsáveis pela tutela do Património Cultural, do verdadeiro significado da profissão do conservador-restaurador, sendo os trabalhos de preservação dos bens culturais muitas vezes adjudicados a pessoal sem formação neste campo ('restauradores': artificies; marceneiros; pintores-decoradores; pintoresrestauradores; pintores-douradores), e/ou sem experiência em conservação e restauro na área do bem cultural a tratar. Verifica-se a ausência de: cooperação interdisciplinar, de critérios éticos e científicos e de espírito crítico na avaliação das consequências das acções empreendidas. A adjudicação do tratamento dos bens patrimoniais tem muitas vezes como primeiro critério o orçamento mais baixo, seguido do menor prazo de execução, e por último do CV de Conservadores-restauradores experientes, não podendo estes profissionais competir com os preços praticados por profissionais não qualificados. Contudo, intervenções acríticas implicam mais gastos 
a curto prazo, a sobreposição de intervenções, e em última análise a perda de integridade material (técnica), histórica e estética do bem cultural. Não será um melhor investimento para o Património Cultural e para a Economia, realizar intervenções baseadas no 'melhor interesse' do bem cultural e não em vantagens políticas, económicas, etc.? Será que a consciencialização dos proprietários em geral sobre o valor de um trabalho de conservação e restauro de elevada qualidade, i.e., baseado na excelência e não na mediocridade, assente em critérios científicos resultantes da colaboração interdisciplinar, não poupa dinheiro a longo termo?

Tendo em conta que, devido à falta de critérios científicos, se perderam irreversivelmente camadas cromáticas originais na pintura "Visitação", propomos que se reflicta sobre como evitar que situações semelhantes se repitam.

Segundo Cruz, a respeito da 'des-remodelação' acrítica de dois dípticos expostos na igreja de São Tiago em Tavira, "nem a questão de se saber o que fazer nessas situacōos é problematizada, pelo menos nas publicacões mais acessivieis, nem está feita a história dos problemas de conservação e museologia dai resultantes" (Cruz 2005: 44).

O mesmo autor apresenta uma reflexão de Vítor Serrão, referente ao caso das pinturas de Tavira: "Há que repensar muito profundamente os critérios que levam, em casos de pinturas sobrepostas, a optar sempre pela conservação do testemunho mais antigo, como se a antiguidade fosse o único principio na conjuntura fíavel, esquecendose que é a qualidade plástica, o valor testemunhal, a importância iconográfica, que devem prevalecer" (Serrão 2003, cit. Cruz 2005: 43).

Cada acção de 'des-remodelação' (remoção de uma 'remodelação') ou de "des-restauro"5 deve ser precedida de um projecto interdisciplinar, no qual os conhecimentos do conservador-restaurador, do curador, do historiador de arte, do químico, do físico e do biólogo são complementares e onde deveria imperar a dialéctica.

Na problemática do "des-restauro" (Tollon 1995: 9-12), devem ser considerados três parâmetros:

i) Técnico (implica a análise das técnicas utilizadas no bem cultural - original e ulterior(es) -, do estado de conservação da obra, da resistência dos materiais originais e ulteriores a qualquer intervenção de "des-restauro", não esquecendo o progresso tecnológico);

ii) Histórico (testemunho de uma época);

iii) Estético.

$\mathrm{Na}$ dialéctica do "des-restauro" (com critérios que também servem para operações de "desremodelação"), o parâmetro estético nunca deve ser dominante, dada a sua "aleatoriedade" (Tollon 1995: 13). Os argumentos estéticos que hoje nos levam a ajuizar que um restauro (ou 'remodelação') adultera a leitura de uma obra, no futuro podem dar lugar a outros critérios estéticos diferentes, devido à subjectividade humana.

A decisão de remover sempre a camada cromática superficial quando se detecta outra pintura subjacente levou a que certas obras sofressem as vicissitudes da 'des-remodelação'. As pinturas de Tavira mencionadas, que antes da última intervenção apresentavam uma 'remodelação' integral do século XVI, estão expostas com partes correspondentes a três períodos históricos diferentes, relativos aos séculos XV, XVI e XX. No caso da "Visitação" foram removidas camadas cromáticas em diversos locais mostrando o que os intervenientes pensavam ser uma pintura mais antiga, quando se tratava da técnica do mesmo pintor. A aposta na preservação de expressões artísticas mais remotas - e por isso mesmo mais valorizadas - era uma prática comum nas intervenções do Estado Novo, influenciadas pelas teorias violetianas defensoras da unidade de estilo, com particular 
enaltecimento do estilo Gótico. No Estado Novo, Gomes da Silva concluía que "o restauro deve ser feito de modo a integrar o monumento na sua beleza primitiva expurgando-o de excrescências posteriores" (Neto 2002 a: 259). Conclusão seguida como critério pela Direcção Geral de Edifícios e Monumentos Nacionais (DGEMN) no restauro do património arquitectónico português, que reflecte alguns dos princípios enunciados cerca de um séculos antes por Viollet-le-Duc. Norma utilizada ainda hoje noutras áreas da Conservação e Restauro de bens culturais, tais como na pintura de cavalete, na pintura mural e na escultura.

Hoje, numa época em que se fala de "autenticidade", que inclui as "várias transformações [num bem cultural,] que ocorreram no tempo" (Cracóvia 2000, cit. Neto 2002 b: 98), com valor de testemunhos, intervenções de 'des-remodelação' ou de "des-restauro" não deverão ser regra, apenas excepção criteriosamente fundamentada. De acordo com um estudo de Marie Berducou (Berducou 1990, cit. Le Gac 1998: 39), realizado cerca de uma década antes do sucedido na "Visitação", e segundo a Carta de Cracóvia de 2000, o conceito de "autenticidade" inclui de facto três noções essenciais: a "durabilidade", a "integridade" e a "acessibilidade" da obra a preservar, que visam respeitar a sua vulnerabilidade, o seu carácter inviolável e a potencialidade de novos conhecimentos que representa. A 'intervenção mínima' favorece o respeito pela "autenticidade" da obra.

Raul Lino, na sequência de inúmeros erros de 'conservação e restauro' da DGMEN no Estado Novo, deixa o conselho intemporal que cremos também seja adequado para áreas distintas da Arquitectura, tais como a Pintura de cavalete: "acabar de vez com o inveterado e ferrenho conceito de restituir à sua primitiva traça que tão grandes malefícios havia já perpetrado por câ” (Neto 2002 a: 268).

Será que em casos como o da "Visitação" de Thomás, de pinturas totalmente recobertas por uma camada opaca (caso também de duas pinturas de Fernão Gomes colocadas c. 1700 na tribuna barroca da igreja de Santa Maria de Setúbal - Serrão 2005: 24), não se deverá reflectir em equipa interdisciplinar sobre os benefícios e as contra indicações de uma 'des-remodelação'? Será que essas "remodelações" não constituem em si um testemunho importante a preservar, revelador da forma de agir numa determinada época? Será que em certos casos não nos deveremos contentar com a radiografia da obra oculta, como prova material da sua existência, em vez de proceder ao "desrestauro" ou à 'des-remodelação', ou seja, à remoção pura e simples de estratos posteriores? Esta remoção é muitas vezes nefasta, como o pudemos constatar no caso aqui apresentado.

De facto a descoberta da "Visitação" em 1998 constituiu um importante contributo para a história da pintura maneirista portuguesa, em particular para a obra do grande mestre Thomás Luís. Antes deste achado, o artista já era conhecido como pintor das modalidades de óleo e de fresco, mas apenas se conheciam obras realizadas nesta última técnica. A nosso ver, a eliminação de várias camadas sobrepostas não foi suficientemente ponderada, assentando em critérios científicos.

\section{1 - Acções de formação sobre os conteúdos de conservação e restauro}

É quase incompreensível que este case study seja tão recente. Parece-nos que uma intervenção de conservação e restauro bem sucedida a nível científico implica acções preliminares e constantes de formação sobre os conteúdos de Conservação e Restauro (significados; ética; critérios de intervenção). Até 1998, existiam já numerosos estudos internacionais sobre Conservação e Restauro, dos quais salientamos aqui alguns.

Considerando uma das competências do conservador-restaurador, ratificada pelo Código de ética (CE) da European Confederation of Conservators-Restorers' Organization (ECCO) em 1993, que consiste em "promover um entendimento mais profundo da conservação e restauro" (ECCO 1993; cit. Seruya 2001: 16), acreditamos que este "entendimento" poderá ajudar a evitar problemas de conservação e restauro, mas só existirá quando se compreender: 
i) Quem é o conservador-restaurador;

ii) Qual é a formação do conservador-restaurador;

iii) Quais são as funções do conservador-restaurador - terminologias e conteúdos;

iv) O que distingue o conservador-restaurador das outras "profissões afins".

\section{Quem é o conservador-restaurador?}

O conservador-restaurador é o profissional que tem a responsabilidade e a preocupação pela preservação dos bens culturais. As suas funções são definidas mais à frente.

Sendo, a conservação-restauro semelhante à "medicina" (Bergeon 1990: 14) e o conservadorrestaurador como um "médico" (Boito [1836-1914], cit. Silva 2002: 215; Dignard 1997) a autora fez os seguintes paralelismos: "Tal como o médico, também ele com base no conhecimento intrínseco do seu código deontológico, formação especializada e acreditada, estudo e experiência constantes, é responsável pelo estudo e tratamento de bens únicos. Realiza um dossier cientifico preliminar sobre a estrutura e a 'bistória clínica' do bem, recorre a métodos de exame e análise físicos e químicos e diagnostica patologias. Em equipa interdisciplinar define quais os intervenientes necessários e os tratamentos preventivos, curativos (...) e de estética indispensáveis e exequiveis, baseados em princípios de reversibilidade, estabilidade e compatibilidade, que respeitem o melhor interesse do bem a preservar" (Cordeiro 2010 a: 84).

O conservador-restaurador é o profissional que tem conhecimento dos riscos que acarreta cada intervenção. Em 1984 o International Council of Museums-Committee for Conservation refere que o conservador-restaurador, tal como o "cirurgião", está habilitado a "avaliar uma situação, actuar imediatamente, e avaliar o seu impacto" (ICOM-CC 1984, cit. Seruya 2001: 11).

O conservador-restaurador é o elemento fulcral numa equipa interdisciplinar. Como refere Agnès Le Gac, ex-Presidente da Associação Profissional de Conservadores-Restauradores de Portugal (ARP), criada em 1995 (Diário da República No 216/95, III Série) "qualquer processo de actuação sobre o património deveria contar com a participaşão imprescindivel do Conservador-Restaurador (...) elo de ligação e (...) elemento activo no diálogo interdisciplinar" (Le Gac 1996 a: 10-11). "É indispensável que as autoridades reconheçam e aceitem a posição do conservador-restaurador neste triumviratus de interesses (historiador de arte conservador-restaurador - cientista], mas infelizmente nem sempre é este o caso" (Philippot 1960: 61).

\section{Qual a formação do conservador-restaurador?}

As intervenções de conservação e restauro deverão ser efectuadas por experts i.e., por conservadores-restauradores com formação acreditada ${ }^{2}$ e experientes na área do bem cultural a tratar,

Em 1984, o ICOM indica que a formação do conservador-restaurador deverá ser de grau universitário. A formação teórico-prática deve assentar numa sólida formação geral (abrangendo matérias como História da Arte, Química, Física e Biologia), estágio finalizado com uma tese ou dissertação final, dando "ênfase principal à prática, nunca perdendo de vista a necessidade de desenvolver e afinar uma compreensão dos factores técnicos, científicos, históricos e estéticos. O objectivo final da formaşão é o de preparar profissionais aptos a realizar, de forma ponderada, intervenções de conservação muitíssimo complexas [tais como este case study] e a documentá-las integralmente" (CE ICOM-CC 1984, cit. Seruya 2001: 13).

Em 1996, Agnès Le Gac, preocupada com este assunto, no artigo "Panorama sobre a Formação do Conservador-Restaurador" apresenta uma compilação bibliográfica de estudos realizados entre 1986 e 1997 (Le Gac 1996 b: 24-28). 
Em 2003, a ECCO e a European Network for Conservation-Restoration Education (ENCORE), criaram o Documento "Educação e acesso à profissão de conservador-restaurador", que insiste na importância da experiência profissional: "Um conservador-restaurador com a habilitação de grau de mestre estará qualificado para se inscrever no PhD. Para se tornar um conservador-restaurador profissional pode the ser solicitado determinados anos de experiência [se ainda não adquirida], após a sua formação, consoante os requerimentos determinados pela organização de conservadores-restauradores nacional, no sentido de confirmar a sua capacidade de trabalhar eticamente, com competência e total responsabilidade na especialidade escolbida" (ECCOENCORE 2003).

Em 2009, o Diário da República insiste igualmente na importância da experiência, referindo que "um técnico babilitado [conservador-restaurador]" tem "formação superior de cinco anos em conservação e restauro e cinco anos de experiência profissional após a obtenção do título académico (...) relevantes na respectiva área de especialidade e no âmbito das obras ou intervençôes em causa". Em casos excepcionais, poderá ter formação académica inferior, mas é exigido o mesmo tempo mínimo de experiência profissional (MC 2009: D-L 140/2009, Cap. IV, Art. 18. ${ }^{\circ}$ ).

\section{Quais são as funções do conservador-restaurador - terminologias e conteúdos?}

Em 1984 o ICOM refere que a actividade do conservador-restaurador compreende o "Exame" técnico, a "Preservação" e o "Restauro", acções devidamente circunscritas e apresentadas por ordem de prioridade, contrariamente ao ocorrido na intervenção de 1998, na "Visitação" de Thomás. O "Exame" é o "procedimento preliminar efectuado para determinar o significado documental de um artefacto; estrutura e materiais; amplitude da sua deterioração, alteração e perda; e a documentação destes resultados". A "Preservação" (que incluiu a "conservação preventiva" e a "conservação curativa", terminologias adoptadas posteriormente, como veremos) envolve "as medidas tomadas para retardar on prevenir a deterioração on danos de bens culturais através do controlo do meio ambiente e/ ou tratamento da sua estrutura, com a finalidade de os manter, tanto quanto possivel, num estado inalterado". O "Restauro", etapa final, facilita o entendimento da obra: "É a acção empreendida para tornar compreensivel um artefacto deteriorado ou danificado, com o minimo de sacrificio da sua integridade estética e histórica" (ICOM-CC 1984, cit. Seruya 2001: 10).

Em 1990 um estudo pioneiro em Portugal de Adília Alarcão procurando fazer uma consciencialização sobre a importância do conhecimento profundo dos conceitos "preservação", conservação" e "restauro" (terminologias da época, correspondentes às actuais "conservação preventiva", "conservação curativa" e "restauro"), demonstra que as acções da conservaçãorestauro seguem uma hierarquia: "Preservar é um dever iniludivel e permanente; conservar é uma necessidade mais ou menos urgente; restaurar é uma opção que pode sempre aguardar" (Alarcão 1990: 4).

O ICOM-CC, no $15^{\circ}$ Encontro Trienal, sob o tema "Terminologia para a definição da conservação-restauro do património cultural material" (Nova Deli, 22-26 de Setembro, 2008), constatando que uma proliferação desordenada de terminologias? tem contribuído para "confusões e mal-entendidos", criou uma nomenclatura para facilitar a "comunicação entre os seus membros, o ICOM, a comunidade profissional internacional e o público em geral'. Adoptou as seguintes terminologias: conservação-restauro (que inclui acções de "conservação preventiva", "conservação curativa" e de "restauro"); conservação preventiva, que abrange "medidas ou acções que tenham como objectivo evitar ou minimiz̧ar futuras degradaçoes ou perdas de leitura e de material, partindo do contexto ou ambiente circundante de um bem cultural"; conservação curativa, que implica "acçôes que incidem directamente sobre o bem ou grupo de bens culturais, com o objectivo de deter processos de degradação activos ou reforçar a sua estrutura"; restauro, que engloba "as aç̧ões exercidas de forma directa sobre um bem cultural em condição estável que tenham como objectivo melhorar o seu usufruto, compreensão e uso" (Figueira 2007: 55-56). 


\section{Qual a distinção entre o conservador-restaurador e as profissões afins?}

Para evitar problemas de conservação e restauro idênticos ao deste case study, é fundamental o conhecimento de um "critério básico" da distinção entre as actividades do "conservador-restaurador" e as praticadas por "profissões artísticas" ou "por artifices" que "assenta no facto dos conservadores-restauradores não criarem novos objectos culturais através das actividades que exercem" (CE ICOM-CC 1984, cit. Seruya 2001: 12). As profissões afins não têm como objectivo a preservação dos bens culturais: "Enquanto que o artista ou o artesão estão envolvidos na criação de novos objectos ou na manutenção e restauro desses objectos, num sentido funcional, o Conservador-restaurador tem como preocupação a preservação dos bens culturais" (CE ECCO 1993, cit. Seruya 2001: 16).

\section{2 - Acções de inspecção e assistência}

No sentido de evitar que sejam abertas mais "feridas" noutros bens culturais, o CE da ECCO (1993) acima referido, acrescenta sete competências ao conservador-restaurador de que salientamos as duas primeiras:

“(i) Desenvolver programas de inspecção e acções de conservação e restauro;

(ii) Emitirpareceres técnicos e dar assistência técnica para a conservação e restauro dos bens culturais" (Idem).

Esta função foi reiterada na Carta de Cracóvia 2000 que refere que "a protecção e conservação do património será mais eficaz se se levarem a cabo (...) acções legais (...) direccionadas de modo a assegurar que (...) estejam sob a supervisão de profissionais da conservação [conservadores-restauradores acreditados']" (C. Cracóvia 2000, cit. Neto 2002 b: 98).

Os problemas de conservação desencadeados na "Visitação" de Thomás Luis em 1998 poderiam ter sido evitados se, na remoção da tinta branca que cobria cerca de $90 \%$ da obra, se desse prioridade ao factor técnico na problemática do "des-restauro", uma vez que o estético tem uma dimensão subjectiva conforme vimos. Tendo em conta a importância do princípio da 'intervenção mínima', é um dever ético fundamental do conservador-restaurador "nunca (...) remover materiais dos bens culturais, a não ser que seja estritamente indispensável para a sua preservação (...)" (ECCO 1993, cit. Seruya 2001: 17).

Qualquer intervenção deve ser precedida de um estudo interdisciplinar aprofundado e cabe ao conservador-restaurador o "papel preponderante" (Le Gac 1996 a: 11) entre os vários especialistas intervenientes, pois é sua a responsabilidade de respeitar o "melhor interesse" de cada bem cultural "unicum"(Brandi 1977: 29), a sua "autenticidade", memória do passado a transmitir às gerações presentes e futuras.

\section{Agradecimentos}

A autora agradece à Fundação para a Ciência e Tecnologia a sua Bolsa de Doutoramento, ao seu orientador Professor Doutor Vítor Serrão e à sua co-orientadora Professora Doutora Agnès Le Gac pelo seu apoio e opinião crítica. Agradece igualmente à Engenheira Isabel Ribeiro do Laboratório C\&R JF do IMC IP, pelos resultados das análises, à firma Veritage, Preservação de Bens Culturais Lda. pelo relatório dos exames e análises da "Visitação" de Thomás Luís, à Professora Doutora Maria João Neto pelo seu incentivo, à Dra. Nazaré Escobar do IMC IP e a João Gaspar, Provedor da SCM do Montijo pela sua disponibilidade, e às Professoras Doutoras Ana Calvo e Rocio Bruquetas da Ge - Conservación. 


\section{Créditos fotográficos}

Figura 4: SCM do Montijo.

Figura 7 e 9: Veritage, Preservação de Bens Culturais Lda. (ex R C Lda./ e IMC IP/ Lab. C\&R JF (ex IPCR/ DEM).

Figuras restantes: Veritage, Preservação de Bens Culturais Lda. - CORDEIRO, F. R..

\section{Referências}

[1] Curador: "Do lat. Curator]. 1. s.m. Administrador dos bens ... de um ausente” (Figueiredo 1996: 754). Em Portugal são usadas duas terminologias para a mesma profissão - Curador ou Conservador de museu. Neste artigo adoptamos a primeira designação, também utilizada no Seminário de Doutoramento “Museologia e Curadoria”, leccionado pelo Professor Doutor Fernando Grilo em 20082009, no IHA da FLUL.

[2] Pintura de construção: camadas cromáticas de construção do quadro, que o artista ocultou em parte quando da aplicação da camada cromática final que define os motivos artísticos.

[3] Camada pictórica: esta nomenclatura tem diferentes significados consoante os países. Neste artigo adoptou-se o conteúdo da terminologia francesa do Service de Restauration de Peintures des Musées Nationaux (SRPMN), segundo o qual a couche picturale é constituída pelos estratos acima do suporte "encolagem; preparação"; "camada colorida (camada de cor propriamente dita e velaturas)" designada no presente estudo como camada cromática; e "camada de protecção" (Cordeiro 1995: 265). Neste artigo adicionámos ao esquema francês uma camada: a impressão.

[4] Impressão: segundo o Glossário Multilingue "quando a preparação, a cola, é totalmente coberta por uma camada saturada de óleo, pigmentada ou não, a esta camada chama-se impressão" (Mendonça et. al. 1993: 43). Em certos casos, este estrato é constituído por mais de um aglutinante e aplicado apenas em parte da obra. Sinónimo de "imprimadura" (Nunes-1615, 1982: 109) e "imprimitura" (Perusini 1985: 217; CCI 1994: 6). Neste artigo utilizamos a terminologia adoptada por Portugal no Glossário acima referido.

[5] "Des-restauro": definição segundo Tollon para a remoção dos restauros em obras que sofreram intervenções a partir do século XIX e para casos excepcionais de setecentos. Embora Perusini refira que, desde a antiguidade, temos notícia de intervenções em obras de arte, corrobora esta ideia de que acções de restauro apenas surgem no século XVIII, embora não conforme o conceito actual de restauro.

[6] Acreditação do conservador-restaurador: http://www.arp.org.pt

[7] "Exemplos: conservação, conservação activa, conservação curativa, conservação directa, conservação indirecta, conservação material, conservação passiva, conservação preventiva, estabilização, gestão de colecções, manutenção, preservação, preservação directa, preservação indirecta, prevenção, proteç̧ão, [restauro], restauro cosmético, restauro curativo, restauro preventivo, reabilitação, renovação, restituição, tratamento, etc.” (Figueira 2007: 55).

\section{Bibliografia}

ALARCÃO, A., Coord., (2005). Conservar é conbecer. Coimbra: Museu Nacional Machado de Castro/ Instituto dos Museus e da Conservação.

ALARCÃO, A. (1991). Conservação e Restauro. Lisboa: Estudo inédito, ESCR.

BERGEON, S. (1990). "Science et Patience" on la Restauration des Peintures. Paris: Ed. Réunion des Musées Nationaux.

BRANDI, C. (1977). Teoria del Restauro, (1ª ed. 1963). Torino: Giulio Einaudi. 
CALvO, A. (1997). Conservación y Restauración, Materiales, Técnicas y Procedimientos, de la A à la Z. Barcelona: Ed. Serbal.

CCI (1994). "Condition Reporting - Paintings. Part III: Glossary of Terms”. En CCI Notes 10/11, Ottawa: Communications Canada.

CORDEIRO, F. R. (1995). Estudo e tratamento de duas pinturas: "Santa Catarina de Alexandria", do século XVI; "Anunciação do Anjo a Nossa Senhora", do século XVII. Lisboa: Tese inédita, ESCR.

CORDEIRO, F. R. (2004). "Estudo e Conservação de uma pintura de Francesco Trevisani”. En Património Estudos, Lisboa: IPPAR/DE, 6: 186-203.

CORDEIRO, F. R. (2005). “A Visitação da Virgem, de Tomás Luís. Relatório científico do tratamento da pintura sobre madeira". En Tomás Luís e o Retábulo da Igreja da Misericórdia, Serrão, V.; Cordeiro, F.R.. Lisboa: Edições Colibri/ Câmara Municipal do Montijo, Cap. II: 51-87.

CORDEIRO, F. R. (2008). Tomás Luís, pintor maneirista do sacro e do profano: história, conservação e restauro. Lisboa: inédito, projecto de candidatura a doutoramento, IHA/FLUL.

CORDEIRO, F. R. (2009 a). Olhar de perto Thomás Luis e a "Visitação": Teoria da Arte e Fortuna Crítica, Seminários de Doutoramento leccionados pelo Professor Doutor Vítor Serrão. Lisboa: Estudo inédito, IHAFLUL.

CORDEIRO, F. R. (2009 b). Estudo e tratamento cientifico da "Visitação" de Thomás Luis: Dialéctica do Restauro, Ciência e Consciência do Património, Seminários de Doutoramento leccionados pela Professora Doutora Maria João Neto. Lisboa: Estudo inédito, IHA-FLUL.

CORDEIRO, F. R. (2010 a). “A Visitação, de Thomás Luis”, Actas das II Jornadas da ARP, A Prática da Teoria, Tratamentos de Conservação e Restauro, 29 e 30 de Maio, MNAA, Lisboa: 73-87, en http://www.ciarteblog.blogspot.com/2010/01/actas-das-ii-jornadas-da-arp.html.

CORDEIRO, F. R. (2010 b). “The Visitation of the Blessed Virgin Mary, by Thomás Luis”, e-conservationline magazine, 13: 78-93, en http://www.e-conservationline.com/content/view/866/288/

CRUZ, A. J. (2005). "Imagens em transformação: os painéis da igreja de Santa Maria, de Tavira, encontrados na ermida de São Pedro, e os problemas colocados pelo seu restauro e estudo laboratorial". En Conservar Património, Lisboa: ARP, 2: 29-53.

CRUZ, A. J. (2007). "Em busca da imagem original: Luciano Freire e a teoria e a prática do restauro de pintura em Portugal cerca de 1900”. En Conservar Património, Lisboa: ARP, 5: 67-83.

DERRICK, M.; STULIK, D.; LANDRY, J. (1999). Infrared Spectroscopy in Conservation Science. Los Angeles: The Getty Conservation Institute.

DIGNARD, C.; DUMKA, H.; MARSHALL, J. (1997). Profession: Restaurateur, Conserver les Oeuvre du Passé pour le Futur, Ottawa: Canadian Association for Conservation of Cultural Property (CAC)/ Canadian Association of Professional Conservators (CAPC).

ECCO-ENCORE (2003), en http: // www.encore-edu.org

FELLER, R. L.; STOLOW, N; JONES, E. (1985). On Picture Varnishes and their Solvents. Washington: National Gallery of Art.

FIGUEIRA, F. (2007). "Terminologia para a definição da conservação-restauro do património cultural material, Resolução aprovada pelos membros do ICOM-CC durante o $15^{\circ}$ Encontro Trienal, Nova Dehli, 2226 de Setembro de 2008", tradução e adaptação da versão francesa. En Conservar Património, Lisboa: ARP, 6: $55-56$. 
FIGUEIREDO, C. (1996). Dicionário de Lingua Portuguesa. Venda Nova: Bertrand Editora.

IMC IP/ Lab. C\&R JF (2004). Visitação da Virgem. Lisboa: relatório inédito.

LE GAC, A. (1996 a). "Deontologia e Formação do Conservador-Restaurador. A criação da ARP”, Boletim da Associação para o Desenvolvimento da Conservação e Restauro, Lisboa: ADCR, 5: 10-11.

LE GAC, A. (1996 b). "Panorama sobre a Formação do Conservador-Restaurador", Boletim da Associação para o Desenvolvimento da Conservação e Restauro, Lisboa: ADCR, 5: 24-28.

LE GAC, A. (1998). "Tudo o que você quis saber sobre o 'Coche dos Oceanos' e nunca ousou perguntar. Ou sobre o conceito de Autenticidade e a ética de uma apresentação museológica”. En Boletim da Associação para o Desenvolvimento da Conservação e Restauro, Lisboa: ADCR, 8/9: 37-43.

LOPES, A. (2010). com. pess.

MENDONÇA, M.; PARENTE, C.; ALVES, L. et. al. (1993). CD Rom Narcisse, Glossário Multilingue. Lisboa: Arquivos Nacionais Torre do Tombo.

MINISTÉRIO DA CULTURA (2009). Decreto-Lei n¹40/2009 (15 de Junho). "Diário da República". 1. série. N. ${ }^{\circ} 113$. Regime jurídico dos estudos, projectos, relatórios, obras ou intervenções sobre bens culturais classificados, ou em vias de classificação, de interesse nacional, de interesse público ou de interesse municipal.

NETO, M. J. (1995). A Direção dos Edifícios e Monumentos Nacionais e a Intervenção no Património Arquitectónico em Portugal (1929-1960). Volume I. Lisboa: Tese de Doutoramento inédita, Faculdade de Letras da Universidade de Lisboa.

NETO, M. J. (2002 a). "Raul Lino ao serviço da Direcção-Geral dos Edifícios e Monumentos Nacionais. Uma nova perspectiva de intervenção". En Artis - Revista do Instituto de História da Arte da Faculdade de Letras de Lisboa, 1: 253-269.

NETO, M. J. (2002 b). “Carta de Cracóvia 2000, Os princípios de restauro para uma nova Europa”. En Património Estudos, Lisboa: IPPAR/DE, 3: 93-99.

NUNES, P. (1982). Arte da Pintura, Symmetria e Perspectiva, Fac-simile da Edição de 1615. Porto: Editorial Paisagem.

PERUSINI, G. (1985). Il Restauro dei Dipinti e delle Sculture Lignee: Storia, Teorie e Tecniche. Udine: Del Bianco Editore.

PHILIPPOT, P. (1960). "Réflexions sur le problème de la formation des restaurateurs de peinture et de sculpture". En Studies in Conservation, IIC, 5: 61-64.

RUIZ-MATEOS, M. (1994). Conservadores y Restauradores en la Conservación y Restauración de Bienes Culturales, Estudio del perfily de la formación. Sevilla: Gráficas Olimpia S.L.

SCMM (2004). Ofício ref. ${ }^{a}$ 614/04, 07/12/2004. Montijo: Documentação fotográfica inédita.

SERRÃO, V. (2002). "O pintor maneirista Tomás Luís e o antigo retábulo da Igreja da Misericórdia de Aldeia Galega do Ribatejo (1591-1597)". En Artis - Revista do Instituto de História da Arte da Faculdade de Letras de Lisboa, 1: 211-235.

SERRÃO, V.; CORDEIRO, F.R. (2005). Tomás Luís e o Retábulo da Igreja da Misericórdia. Lisboa: Edições Colibri/ Câmara Municipal do Montijo. 
SERRÃO, V. (2005). "O pintor maneirista Tomás Luís. A Visitação da Virgem a Santa Isabel, da igreja da Misericórdia do Montijo (1591-1597)”. En Tomás Luís e o Retábulo da Igreja da Misericórdia, Serrão, V.; Cordeiro, F.R.. Lisboa: Edições Colibri/ Câmara Municipal do Montijo, Cap. I: 11-50.

SERRÃO, V. (2006). “《Renovan», «repintan», «retocan»: estratégias do pintor-restaurador em Portugal, do século XVI ao XIX. Razões ideológicas do iconoclasma destruidor e da iconofilia conservadora, ou o conceito de «restauro utilitarista» versus «restauro científico»". En Conservar Património, Lisboa: ARP, 3/4: 53-71.

SERrÃo, V. (2008). O fresco maneirista do Paço de Vila Viçosa, Parnaso dos Duques de Bragança (1540-1640). Caxias: Fundação da Casa de Bragança.

SERUYA, A. I., Direc. (2001). Cadernos de Conservação e Restauro. Lisboa: Instituto Português de Conservação e Restauro.

SILVA, A. F. (2002). "A(s) Ciência(s) do Património: Notas para a fundamentação e enquadramento da Conservação e Restauro”. En Revista da Faculdade de Letras, Ciências e Técnicas do Património, 1: 211-220.

TOLLON, F. (1995). "Quelques questions sur la dé-restauration". En Restauration, Dé-Restauration, Rerestauration, 4 ${ }^{i e m e}$ Colloque de l'Association des Restaurateus d'Art et d'Arquiologie de Formation Universitaire, 5-7 Octobre, Paris : ARAAFU, $9-16$

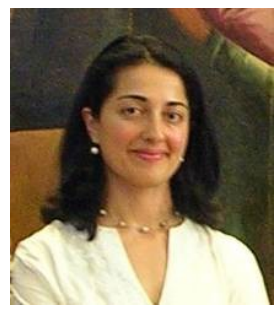

\section{F. Raposo Cordeiro}

f.cordeirofurtado@gmail.com

Filipa Raposo Cordeiro. Doutoranda em Ciências do Património e Teoria do Restauro no IHA/FLUL, Portugal. Conservadora-restauradora com 16 anos de experiência contínuos. Formou-se na ESCR (1991/95). Especializou-se no Opificio delle Pietre Dure (1994/95), no Canadian Conservation Institute (1997/98) e no Victoria \& Albert Museum (1998). Leccionou as Cadeiras de "Conservação e Restauro de Pintura de Cavalete”, Seminários I e II, na FCT/UNL, actual mestrado (2000-2001). Fundadora da firma Veritage, Preservação de Bens Culturais Lda. (2004). Sócia da ADCR e da ARP. Tem um livro de co-autoria e vários artigos publicados.

Artículo recibido el 30/03/2010.

Artículo aceptado el 23/06/2010. 